\title{
Medicalization of Birth in the United States Through the Lens of The Handmaid's Tale
}

\author{
Vicky Zhu ${ }^{1}$ and Carly Thomsen ${ }^{2}$ \\ ${ }^{1}$ The Pennington School, Pennington, NJ, USA \\ ${ }^{2}$ Middlebury College, Middlebury, VT, USA
}

\section{$\underline{\text { ABSTRACT }}$}

The TV series The Handmaid's Tale, based on the bestselling book by Margaret Atwood, provides the audience with a visual experience which leaves them with indelible impressions of social stratification. Inspired by the representation of social hierarchy shown by differences between clothes, protestors in real life have found the costume of the handmaids to be a useful symbol to protest themes related to the TV series in reality, including sexual assault and reproductive rights. However, barely anything is written or discussed about the medicalization of birth around The Handmaid's Tale. Although the medicalization of birth has existed in the United States for a long time, most people are uneducated about its harms. The medical-industrial complex behind the scene positions patients under an unfair medical system that can negatively impact their health. Therefore, this paper shows how the TV series provides a lens through which to reflect the negative aspects of this real-life issue in order to raise public awareness.

\section{Introduction}

The TV series The Handmaid's Tale is based on the bestselling book by Margaret Atwood, published in 1985 . It focuses on the journey of a handmaid named Offred. The TV series of The Handmaid's Tale was first released in 2017, and, due to its popularity, was renewed for two subsequent seasons. Season One is adapted from the book, and the director extends the plot in Seasons Two and Three. Throughout the three seasons, Offred and other handmaids experience different ways and phases of pregnancy, birth and motherhood, casting a lens on what it means to bear children in this disenfranchising social context. The TV series has impressed millions of readers with its patriarchal dystopian society that seems both familiar and unfamiliar. The TV series respects the original plot and ideas of the book, and at the same time enhances its themes by providing a strong visual experience.

The story is set in a fictional dystopian future where a group of Christians overthrow the US government and establish the Gilead Republic, a patriarchal society that significantly disempowers women. Due to nuclear contamination, the birth rate declines significantly, and the republic's next generation faces a threat of near extinction. A group of women is gathered and named as "handmaids": reproductive receptacles for the Gilead Republic. Each is assigned to a host family where they live under the rule of the sterile wife and serve as a walking womb for the family. The handmaids are restricted in many ways, including in their daily activities and reproductive rights. In other words, the handmaids have no autonomy over their own bodies, which are seen as merely vessels for their future child, and which are at the mercy of the host family. There is a ceremony each month for the commander of the host family to impregnate the handmaid. If the coupling is successful, the status of the family rises; however, the handmaid is discarded to a new host family immediately after the birth of her baby. Offred, the protagonist of the TV series, is a strong-willed handmaid who is not willing to surrender to the rules of the Gilead Republic. The TV series shows how Offred struggles, resists and finally escapes from the dystopian society.

Real-life protestors have been inspired by the fashion of the show, wearing the red and white costumes of the handmaid's dress to make a point about women's reproductive rights; this is because many issues discussed in the TV 
series have strong social relevance to the issues that exist in reality. Gender inequality, Planned Parenthood and reproductive rights are protest topics that frequently find connections with the show. In the summer of 2017, a group of 30 women dressed like handmaids - in red cloaks and white bonnets - marched in Washington D.C. to protest the GOP health care bill as anti-women. One member of the group claimed that the handmaid costume from the TV series "[makes] a visual statement and [demonstrates] how serious we take this." By dressing up like the disenfranchised handmaids, the protestors intended to draw parallel between the policies in reality and the totalitarian dystopia depicted in the TV series.

Although the medicalization of birth has a long history in the United States, it has been little studied in relation to The Handmaid's Tale. Despite the frequency with which handmaid's costumes have been used to highlight issues about health care, people have not yet drawn from the show or used the image of the handmaids in order to talk about the medicalization of birth. Similarly, no bloggers, journalists or scholars have utilized the show in order to reflect on issues related to the medicalization of birth. The word "medicalization" is used to describe the phenomenon of frequent use of medical products to treat neither medical nor biological disabilities. The medicalization of birth, unlike other issues that the show brings up, is not widely considered a negative development in society. Yet the documentary The Business of Being Born, directed by Abby Epstein and released in 2008, reveals the problems inherent in the medicalization of birth in the US by exploring how doctors make choices regarding the way their patients give birth and how some common medical practices are more harmful than helpful to the mothers. The film shows that by 1955, fewer than $1 \%$ of births took place at home in the United States. This indicates that Americans tend to believe that medicalized birth is a natural, and even progressive thing to do, yet studies indicate that the United States experiences the highest maternal mortality rate in the western world. The Handmaid's Tale includes scenes about the process and effects of the medicalization of birth which mirror the existing issue of medicalized births in the United States, though people may not be aware of it. Both in the Gilead Republic and in the United States, the medicalization of birth has not always served the best interests of women.

In this paper, I argue that the TV series The Handmaid's Tale depicts the medicalization of birth as a tool for the medical industrial complex to exert control over women by creating an unequal power dynamic. By showing scenes of the process and effects of medicalized birth, the TV series presents Americans' reactions to birth and raises awareness of issues around the medicalization of birth in the US. This research paper starts by providing a review of the previous scholarly discussion related to the medicalization of birth in the United States and its important role in the story of The Handmaid's Tale. Then, in the analysis section, I analyze two scenes from Season 1 of the TV series in terms of how they show that the medicalization of birth creates unequal power dynamics and reflect the same issue in the US. I conclude by suggesting the direction of future studies that can raise public awareness about the issue of the medicalization of birth.

\section{Literature Review}

Feminists and medical professionals have long been concerned with the consequences of the medicalization of birth. According to The Collins Dictionary, the verb "medicalize" means "to use medical methods or concepts in dealing with non-medical problems, conditions." It is important to understand that "medicalize" indicates unwarranted medical treatments. Its noun form, "medicalization," was coined by medical sociologists Thomas Szasz and Peter Conrad, who used this word to describe the phenomenon of frequent use of pharmaceuticals to treat neither medical nor biological disabilities; they argued that medicalization originated from and was powered by the medical industrial complex. Analogous to the phrase "military industrial complex" coined by Former US president Dwight Eisenhower, the medical industrial complex is a network that puts the profits of the public behind those of the stockholders in this market. This emerging industry has raised little attention but creates issues like overemphasis on technologies. Medi- 
calization is a tool of the medical industrial complex to exert valid control over people which aggravates social inequality. Medicalization extends the power of the medical industrial complex and allows them to achieve their lucrative goals.

Currently in the United States, medicalization plays a role similar to the definition in The Collins Dictionary: taking common human and social experiences, labeling them, and treating them with prescriptions and other medical tools. Many previously non-medical problems are defined as new and emerging medical conditions that are harmful but curable with prescribed drugs; some examples of these conditions are adult Attention-Deficit/Hyperactivity Disorder (ADHD) and premenstrual dysphoric disorder. Surprisingly, eight out of these many newly defined conditions affect more than $77 \%$ of the adults in the USA. How could a medical condition that affects such a broad spectrum of the population have only been recently discovered? This indicates a trend in which people tend to believe that these new medical conditions and the pharmaceutical treatments for them are reliable and helpful; this phenomenon benefits both hospitals and drug companies, which manipulate this lucrative industry of medicalization behind the scenes. According to Dr. Carl Elliott, a professor of bioethics at the University of Minnesota, medicalization follows a repeating pattern: "You destigmatize the condition, broaden it to include a much larger patient population, rebrand it or give it a name that is less embarrassing to people." Thanks to medicalization, millions more people in the US consider themselves as having treatable disorders, which are actually unnecessary to treat at all.

Representations of medical and health issues on TV are hugely impactful to an audience's understanding of that issue. Often, it is misrepresented in ways that are harmful to the public understanding of these topics. Abortion, for example, is included in various TV shows as a part of character's life, but many aspects of abortion such as ages of the pregnant women and reasons for abortion are often dramatized or entirely false. Sisson and Kimport, two sociologists from the University of California, provide specific examples of this in their research on abortion in American TV from 2005-2014. They compared the reasons women decide to have an abortion in TV versus in reality. For example, in reality, the percentage of US women claiming "not financially prepared" as the reason was $40 \%$, while the percentage of TV characters arguing the same reason was only $10.5 \%$. This indicates that TV shows can present social issues falsely, either underestimating or exaggerating them. This is important because, as Sisson and Kimport note, representations of abortion on TV influence significantly how audiences view abortion in real life.

Birth is another area of women's health that has been misrepresented in the media and is poorly understood in the general population. Data from the documentary The Business of Being Born suggests that $95 \%$ of births in the US took place at home in 1900, usually with the help of a midwife; however, by 1955 , more than $99 \%$ of births took place at hospitals. This huge shift is likely one of the reasons why the US has the second worst newborn mortality rate among developed countries. The documentary shows how midwives have been misunderstood as poor, unprofessional and even wizardly. However, the successful examples of births with the assistance of midwives depicted in the documentary contrast with this view. Midwives say in the documentary that their purpose is not only to help women to give birth successfully, but also to let women experience this memorable moment in their lives. Due to the medicalization of birth, unnecessary medical interventions such as anesthetics and compulsory C-sections not only leave mothers with memories of pain but may cause them to undergo a painful and difficult delivery. The documentary depicts women who are under the control of doctors and medicines as weak and powerless, showing how medicalization creates an unequal power dynamic which disempowers women.

Besides demonstrating how midwives are often condemned by society, this documentary shows how doctors play a part in the medicalization of birth. The reason why more and more people choose to deliver babies under medical supervision is that birth is depicted in the media as a dangerous and high-risk process when people do it on their own. People lack accurate knowledge about natural births; therefore, they rely on doctors who are trusted to guarantee a safe, non-natural birth. However, under the effects of medicalized births, medical decisions regarding delivery are not always being made for the good of the mother or the baby. During an interview with three OB-GYN doctors in the documentary, when they are asked how often they see a natural birth in a hospital, their response is "barely" and "almost never". The Business of Being Born makes it clear that most medical students have not observed a natural birth; they are trained to be surgeons who prescribe and operate. 
Feminists have long been interested in the way medicalization - of both birth and abortion - has impacted and disenfranchised women. In Medicine and Morality in the Nineteenth Century, sociologist Kristin Luker argues that doctors in the $19^{\text {th }}$ century were involved in abortion politics that didn't medically benefit patients. They intervened in order to achieve their own goals. In the 1800s, physicians were actively involved in the abortion movements, many claiming that abortion was medically and morally wrong. They argued that they became involved with abortion issues because women were ignorant about pregnancy and abortion; the doctors considered themselves as the experts who possessed the newest scientific knowledge. That was partially true, but it was only a cover for their deeper aim. The advantage of being an anti-abortionist was that it enabled them to distinguish themselves from their competitors as more superior in moral and technical expertise; they wanted to increase their reputations to thrive economically. While other medico-moral issues at that time included alcoholism, slavery and prostitution, only abortion provided physicians with the chance to "perform" their responsibilities. Since only six states did not include "therapeutic exception" in abortion laws, physicians consolidated their absolute power and control over women's decisions about abortion; they justified their actions by becoming the custodians of it. This was a kind of medicalization because doctors utilized unwarranted medicine and technology to demonstrate their expertise. Therefore, as Luker shows, as early as the $19^{\text {th }}$ century, doctors started engaging in politics for self-interests and financial gain via their approach to birth and abortion.

The medicalization of birth has always centered on a core belief in the value of children. People are willing to pay high costs to ensure the best birth for their children. In Lee Edelman's book No Future, he argues that the child is the center of the future and of everything: "We are no more able to conceive of a politics without a fantasy of the future than we are able to conceive of a future without the figure of the Child." Of course, the existence of the handmaids in The Handmaid's Tale would not be necessary if the inability to give birth to the next generation was not a concern; in other words, handmaids are gathered to produce children in order to endow meaning to the future. Additionally, the laws and regulations of the Gilead Republic are based on the importance of children. For example, since queer people are not able to give birth to children "naturally", they are considered gender traitors by the leaders of the Gilead Republic, and therefore persecuted. Most importantly, the Gilead Republic emphasizes the importance of children because it considers the child a powerful secret weapon to distract women's attention from other things, like politics. As we can see in the TV series, nearly every conflict between female characters is triggered by children: vain squabbles between wives, comparisons between handmaids about whether they are pregnant, and the restless relationship between the wives and handmaids. Therefore, it is "the Cult of the Child" that moves the story forward. In the following section, I will analyze two scenes from Season 1, Episodes 2, 4, and 6 of The Handmaid's Tale and explain how they relate to the medicalization of birth in the United States.

\section{Discussion}

In Season 1, Episode 4, Offred invents a physical discomfort in order to leave the house for fresh air and is sent to see the doctor. She just wants to temporarily escape from her host family, the Waterfords, for whom she is assigned to bear babies. The private conversation between Offred and the doctor illustrates the medicalization of birth, especially the vulnerability of the handmaids and how the doctors work for the government's or the medical industrial complex's agenda. They limit women's political ability by occupying and distracting them with babies. Assuming that Commander Waterford is sterile because Offred is not pregnant despite months of regular impregnation ceremonies, the doctor offers Offred help by suggesting that he impregnate her, so she won't be blamed or punished for her "infertility". "It will only take a few minutes, honey," he says when peering from behind the curtain. 


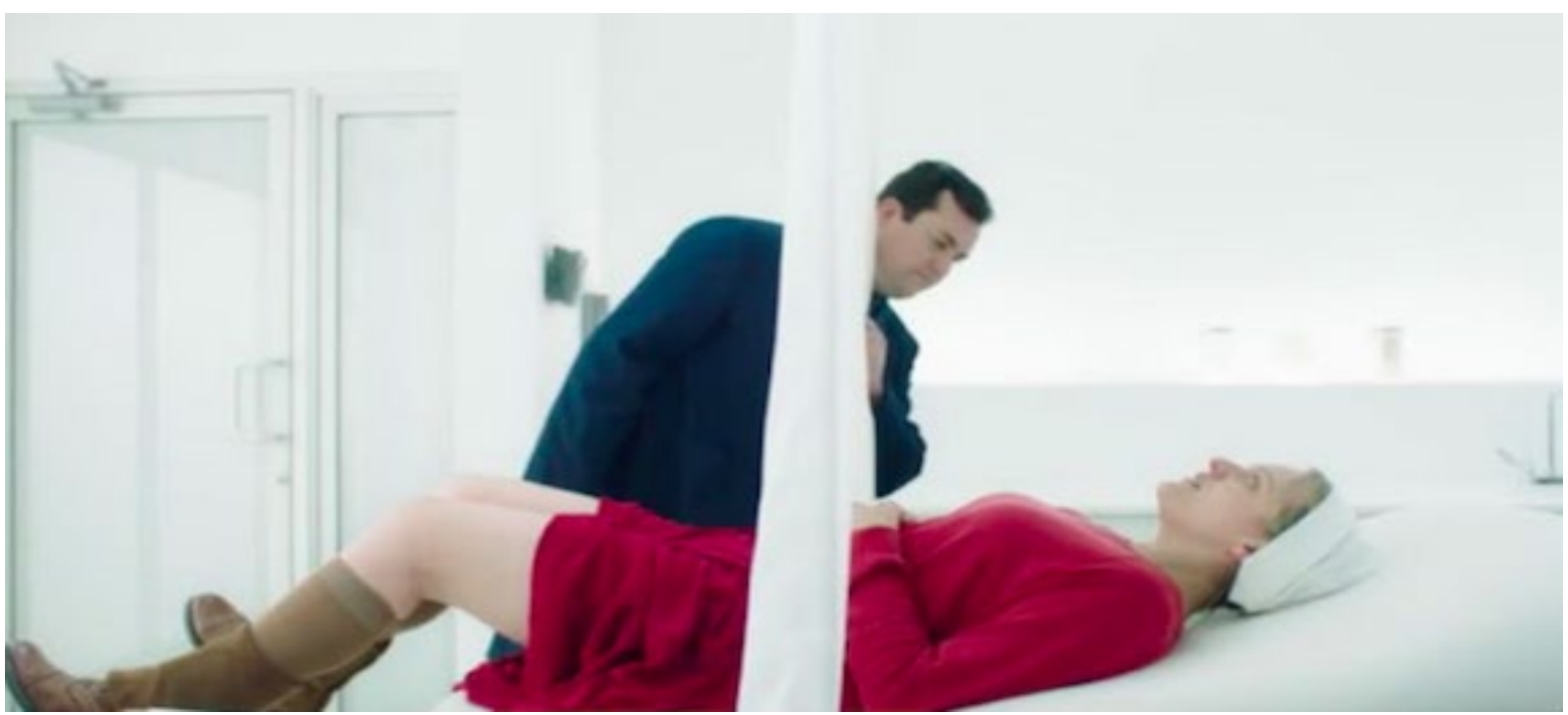

Figure 1. In Season 1, Episode 4, Offred lies on the bed in a hospital when the doctor offers to impregnate her.

In the end, after a silent consideration, Offred says no. The doctor's intention in this scene can be interpreted in two opposite ways. On one hand, the doctor may be making a sincere offer to help Offred avoid blame and punishment. Since he assumes the commander is an infertile male (which is illegal to say in the Gilead Republic), the doctor may be a member of the resistance and want to help the handmaids avoid being labeled as sterile. However, the offer seems suspicious and dangerous to Offred. Indeed, the doctor may be acting for the government of the Gilead Republic as one of the "plain-clothes" Eyes whose job is to arrest those who violate the rules of the republic. Or he may simply want to have sex with the powerless woman lying on the sickbed.

Like Offred, viewers are left not knowing what the doctor's true intention is. The fact that we don't know the best interpretation of the doctor's offer is part of the anxiety troubling Offred's life. Although the doctor's individual motivation is unknown, we know that he serves the Gilead government. The curtain, situated between Offred and the doctor, is useful for further analyzing the scene. When the doctor is behind the half-transparent curtain, he explains in a professional tone that Offred is not suffering from any kind of significant illness, and Offred can only see his blurry facial outline. The curtain prevents Offred from being seen by the doctor directly; it disguises his true identity. The doctor offers to help to impregnate Offred when he peers around from behind the curtain and is visible to her. The doctor does so to humanize Offred by actually looking at her face across the curtain, not only at her vagina which is the only part he is supposed to examine. The pose of Offred lying with her legs open and the position of the doctor standing over her suggests the vulnerability of patients in front of doctors; thus, it shows the unequal power dynamics between patients and doctors that the Gilead government intends to create. Regardless of whether the doctor is an Eye or a member of the resistance, if he were to impregnate her, this would nonetheless support the agenda of the Gilead government whose entire worldview and establishment of a patriarchal society relies on the impregnation of handmaids in order to disempower women. This benefits the government and the medical industrial complex because it helps them to gain control over women in order to establish a patriarchal society in which women are either receptacles or babysitters for children.

In addition, the doctor considers Offred's possible "infertility" a medical issue which can be treated with a "prescription": impregnating her. However, "infertility" may not be an issue that Offred has at all. The infertility could be attributed to Commander Waterford instead. This shows that the government of the Gilead Republic intentionally creates an unequal power dynamic between the two sexes by saying that only infertility in women is considered a medical issue to be treated. In this way the Gilead government achieves its goal of disempowering women.

Before the era of the Gilead Republic, it was common to give birth in hospitals. In a flashback Offred has in Season 1, Episode 6, she recalls giving birth to her daughter, Hannah. Her husband, Luke, drives her to hospital as 
soon as Offred feels a slight discomfort in her stomach. Offred gives birth to Hannah successfully under the supervision of doctors in the hospital. This scene shows that before the formation of the Gilead Republic, sending an expectant mother to a hospital was a typical American's initial and instinctual reaction when she was near delivery.

However, in Season 1, Episode 2, it becomes apparent that birth is treated differently in the republic. Episode 2 focuses on a Birth Day, one of the important events in the Gilead Republic. Unlike the birth in Episode 6, Ofwarren, another handmaid, gives birth to her baby in a non-medicalized way. The scene is not situated in a hospital but at the Warrens' home. Ofwarren is not surrounded by medical machines; instead, she has "aunts", who are mentors to the handmaids, and other handmaids who come as friends to support and comfort her. Aunts shout out instructions, just like midwives, while other handmaids are like close relatives of Ofwarren, clutching her hands and whispering prayers.

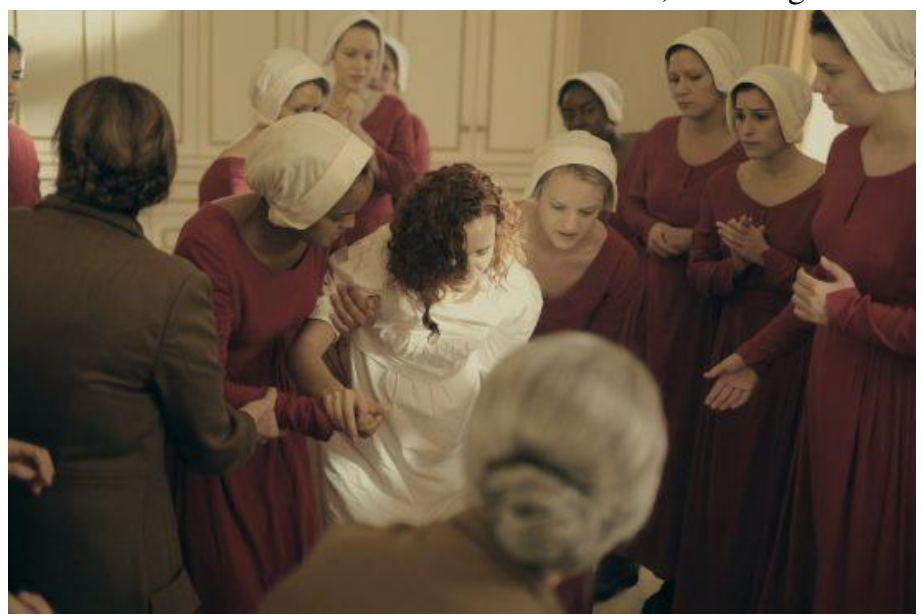

Figure 2. In Season 1, Episode 2, Ofwarren, a handmaid, gives birth to a child with the help from other handmaids and aunts.

Even the wives gather downstairs to witness the birth of the baby, but in a different way. As a tradition, Mrs. Warren acts like she is experiencing this delivery process herself, shouting as if she were trying her best to push the baby out. The birth of Ofwarren's baby is a natural birth without any unnecessary medical interventions. Unlike a medicalized birth in the TV series, Ofwarren experiences the process of giving birth and enjoys her interactions with her baby even though she knows Mrs. Warren will take the baby soon. When the baby gives her first cry, everyone cheers and laughs. It is the only moment in Gilead when women of all classes are united and celebrate the same thing altogether with true happiness; it is also the only moment when women of Gilead experience freedom and enjoy themselves without any interference from men. This Birthday scene suggests how smooth and harmless a natural birth can be even in a society that encourages medicalized births.

These scenes in The Handmaid's Tale show the Americans' contrasting approaches to birth, imbued with emotional implications. On the one hand, Episode 2 depicts a natural birth which takes place at home and is free from unnecessary medical interference. Family members stay to comfort and emotionally support the mother, and midwives give necessary instructions and physical support. On the other hand, Episode 4 and the flashback scene show another group of people whose initial reaction to giving birth is to reach out to hospitals and doctors. They believe that the birth of their children can only be successful under the supervision and with the assistance of doctors and medical technologies. However, they underestimate their own ability to give a natural birth, just like Offred going to the hospital after feeling a slight discomfort. They also overrate the ability of the doctors and overestimate the usefulness of medical technologies. For example, in Episode 2, the birth of Ofwarren's baby is safe and successful without any assistance of the doctors and medical technologies. Additionally, they do not realize the disguised market of medicalization and the hidden purpose of the medical industrial complex behind it. Offred, compared to people in reality, is more alert to doctors and the medical industrial complex since she experiences and knows the rules of the dystopian society, she lives in. However, often left uninformed about general knowledge of birth, Americans may blindly believe 
in doctors who sometimes do not give medical suggestions that benefit their patients, but instead benefit themselves and the medical industrial complex. Doctors may take advantage of the public's ignorance to expand the market of the medicalization of birth, which results in unequal power dynamics between patients and doctors. This inequality makes patients more vulnerable to medicalization and the hidden purposes imposed by the medical industrial complex. In the next section, I move from discussing specific scenes in the TV series of The Handmaid's Tale to broader social implications.

\section{Conclusion}

In reality, people often face the choice of whether to have a natural or a medicalized birth. A main difference between medicalized and natural births is that mothers who participate in natural births do not receive imposed medical treatments in the hospital, but rather experience a birth naturally. Another difference between the two types of births is the atmosphere. In a medicalized birth, scurrying footsteps, cries and sounds of technology are audible everywhere in the hospital. As The Business of Being Born claims, mothers are much more relaxed at home compared to an unfamiliar hospital's chaos. The biggest concern about the issue of medicalized birth is that people do not consider it a negative; instead, they take it as an opportunity to experience the progress and development of advanced medical technologies. People only see advanced medical technologies available at hospitals, but they do not see the market of medicalization and the medical industrial complex working behind the scenes. The Handmaid's Tale highlights how people are often ignorant of the way that doctors do not always make medical decisions based on patients' wellbeing, instead considering the benefits to themselves and the medical industrial complex. The Handmaid's Tale reveals the negative side of the medicalization of birth to raise public awareness of issues around the medicalization of birth.

As I mentioned in the literary review, according to The Business of Being Born, only $1 \%$ of births took place at home in the United States in the last decade, indicating that people consider giving birth in hospitals a natural and correct thing to do. Ignorant of the harms of medicalized birth, people invest their money and belief in the market of the medicalization of birth, further enlarging the market. Thus, feminists should conduct more studies on this topic to raise public awareness of the downsides of medicalized birth. Studies could include topics like the physical harm medical technologies cause, emotional stress after a medicalized birth and the invisible manipulation of the medical industrial complex.

\section{References}

Atwood, M. (2010). The Handmaid's Tale. Vintage.

Crossman, A. (2018, April 17). Medicalization in Sociology. ThoughCo. Retrieved from https://www.thoughtco.com/medicalization-3026407

Edelman, L. (2004). Introduction. No Future, 1-31.

Hamedy, S. (2017, June 27). 'Handmaids' descend upon hill to protest health care bill. CNN Politics. Retrieved from https://edition.cnn.com/2017/06/27/politics/handmaids-tale-health-care-protests/index.html

Krakauer, E., Ph.D. (1991). On Medicine and Politics [PDF]. The Yale Journal of Biology and Medicine, 65, 243249.

Lake, R., \& Netto, P. (Producers), \& Epstein, A. (Director). (2008). The Business of Being Born [Film]. 
Luker, K. (n.d.). Medicine and Morality in The Nineteenth Century: Social and Historical Context.

Medicalize. (n.d.). The Collins Dictionary. Retrieved from https://www.collinsdictionary.com/us/dictionary/eng$\underline{\text { lish/medicalize }}$

Morano, R. (Director). (2017). The Handmaid's Tale [Film]. MGM Television.

Perry, S. (2016, May 23). The Medicalization of America: How It's Making Most of Us 'Sick'. Minnpost. Retrieved from https://www.minnpost.com/second-opinion/2016/05/medicalization-america-how-its-making-most-us-sick/

Relman, A. S., M.D. (1980). The New Medical-Industrial Complex. The New England Journal of Medicine. Retrieved from https://www.nejm.org/doi/full/10.1056/NEJM198010233031703

Sisson, G., \& Kimport, K. (2016). Facts and Fictions: Characters Seeking Abortion on American Television 20052014. Contraception, 93, 446-451. 